\title{
Two-Dimensional Model of Wind Flow on Buildings to Optimize the Implementation of Mini Wind Turbines in Urban Spaces
}

\author{
J.C. Sáenz-Díez Muro ${ }^{1}$, E. Jiménez Macías ${ }^{1}$, J.M. Blanco Barrero ${ }^{1}$, \\ M. Pérez de la Parte ${ }^{2}$, and J. Blanco Fernández ${ }^{2}$ \\ ${ }^{1}$ Department of Electrical Engineering ; ${ }^{2}$ Department of Mechanical Engineering \\ E.T.S.I.I., University of La Rioja. Luis de Ulloa, 20. 26004. Logroño (Spain) \\ Phone/Fax number:+34 941299477 +34 941 299478, \\ e-mail: \{juan-carlos.saenz-diez; emilio.jimenez; juan-manuel.blanco\}@unirioja.es
}

\begin{abstract}
The roofs of the buildings present a very valuable source of renewable energy: wind. Similar to the study of the perfect location for wind generators in the natural environment, we need to have models for characterization of wind in the urban space to optimise the locations of the mini wind turbines in that space as well as the chose of the most appropriate type. The scientific study of the implementation and optimisation are the basis for a line of research developed by our group in recent years. Its most important results and main conclusions are presented in this paper. The separation angle is greater near the edge of the roof of the building and varies with wind speed. The higher the building, the greater the separation angle reached, reaching even $90^{\circ}$. For low buildings that angle will be imperceptible. The more rugged is the area near the building the lower the angle of separation. The wind turbines have to be placed always at a height above the separation bubble, in order to avoid the slow speeds as well as significant turbulences. Furthermore it is noteworthy that the wind turbines will benefit from an increase of $20 \%$ of air velocity compared with the wind at the same location if there was no effect of the building. That is, the urban space provides an extra increase of wind power, provided that the location of wind turbines is optimised.
\end{abstract}

Keywords: Renewable Energy, Wind Power, Mini Wind Turbines, Sustainable Building, Urban Turbines.

\section{Introduction}

The way to sustainability as a new and essential paradigm of our society must lead to the search of energy consumption reduction and to increase the energy efficiency in our buildings, combined with the replacement of fossil fuels by renewable energies.

The most important criteria for the sitting of power plants is the location near to the raw material. Renewables open the door of distributed generation, because dispersed generation can be located wherever it is the precious source of energy.

The roofs of the buildings present a very valuable source of renewable energy: wind $[1,2,6,7]$. Similar to the study of the perfect location for wind generators in the natural environment, we need to have models for characterization of wind in the urban space to optimise the locations of the mini wind turbines in that space as well as the chose of the most appropriate type [3, 4, 5, 9].

The scientific study of the implementation and optimisation are the basis for a line of research developed by our group in recent years. Its most important results and main conclusions are presented in this paper.

The model is based both on simulations and on experimental data, which have been taken for years to validate the simulation models. This allows these models to be verified, validated, and extrapolated to other buildings. A series of simulations have been developed with the application FLUENT (C) (Computational Fluid Dynamics) for evaluation of CT, the increasing roof factor, and to validate its value.

The study has been developed for a specific city (Logroño, Spain) and a concrete building (The Departmental Building, DP, in the campus of the University of La Rioja), simply to present the results, since the methodology is equally valid for any city.

\section{Wind characterisation}

The characterization of the wind speed for the urban space in general and the city of Logroño in particular has been modelled, at a height of 15 meters, obtaining an average speed of $2.4 \mathrm{~m} / \mathrm{s}$, whose wind distribution resembles the Weibull distribution with parameters $\mathrm{k}=2.24$ and $\mathrm{c}=2.70 \mathrm{~m} / \mathrm{s}$. The prevailing wind direction takes two distinct components: WNW, which is called the north wind, and ESE, called muggy. 
Table 1 Tabular data for the wind characterization of the urban space of the city of Logroño ( $\mathrm{Zr}=15 \mathrm{~m}, \alpha=0.39, \mathrm{k}=2.24)$

\begin{tabular}{cccc}
\hline $\boldsymbol{Z}(\boldsymbol{m})$ & $\boldsymbol{C z}$ & $\boldsymbol{c}(\boldsymbol{m} / \mathbf{s})$ & $\boldsymbol{v}_{\boldsymbol{m e d}}(\boldsymbol{m} / \mathbf{s})$ \\
\hline $\mathbf{1 5}$ & 1,00 & 2,70 & $\mathbf{2 , 4 0}$ \\
$\mathbf{1 8}$ & 1,07 & 2,90 & $\mathbf{2 , 5 8}$ \\
$\mathbf{2 1}$ & 1,14 & 3,08 & $\mathbf{2 , 7 4}$ \\
$\mathbf{2 4}$ & 1,20 & 3,24 & $\mathbf{2 , 8 8}$ \\
$\mathbf{2 7}$ & 1,26 & 3,40 & $\mathbf{3 , 0 2}$ \\
$\mathbf{3 0}$ & 1,31 & 3,54 & $\mathbf{3 , 1 4}$ \\
$\mathbf{3 3}$ & 1,36 & 3,67 & $\mathbf{3 , 2 6}$ \\
$\mathbf{3 6}$ & 1,41 & 3,80 & $\mathbf{3 , 3 8}$ \\
$\mathbf{3 9}$ & 1,45 & 3,92 & $\mathbf{3 , 4 8}$ \\
$\mathbf{4 2}$ & 1,49 & 4,03 & $\mathbf{3 , 5 9}$ \\
$\mathbf{4 5}$ & 1,53 & 4,14 & $\mathbf{3 , 6 8}$ \\
$\mathbf{4 8}$ & 1,57 & 4,25 & $\mathbf{3 , 7 8}$ \\
$\mathbf{5 1}$ & 1,61 & 4,35 & $\mathbf{3 , 8 7}$ \\
$\mathbf{5 4}$ & 1,65 & 4,45 & $\mathbf{3 , 9 6}$ \\
\hline $\mathbf{5 7}$ & 1,68 & 4,54 & $\mathbf{4 , 0 4}$ \\
\hline $\mathbf{6 0}$ & 1,72 & 4,64 & $\mathbf{4 , 1 2}$ \\
$\mathbf{6 3}$ & 1,75 & 4,73 & $\mathbf{4 , 2 0}$ \\
$\mathbf{6 6}$ & 1,78 & 4,81 & $\mathbf{4 , 2 8}$ \\
$\mathbf{6 9}$ & 1,81 & 4,90 & $\mathbf{4 , 3 5}$ \\
$\mathbf{7 2}$ & 1,84 & 4,98 & $\mathbf{4 , 4 2}$ \\
\hline & & & \\
\hline
\end{tabular}

For the wind characterization on buildings in the city of Logroño, the height coefficient $\mathrm{Cz}$ should first be calculated (coefficient developed by the authors). For an average dominant height of the roughness elements of $35 \mathrm{~m}$, we obtain a roughness parameter, $\mathrm{Z}_{0}=1.167 \mathrm{~m}$. Thus the parameter $\alpha$, according to the proposed models, is 0.39 . Keep in mind that $\alpha$ varies with the atmospheric instability of the day, so correlations should be made with taken this into account.

Once calculated $\mathrm{Cz}$, the wind speeds $(\mathrm{m} / \mathrm{s})$, average speeds $(\mathrm{m} / \mathrm{s})$ and the Weibull scale factor $\mathrm{c}(\mathrm{m} / \mathrm{s})$ are scaled, and the form factor, $\mathrm{k}$, remains constant. All this can be appreciated in Table 1 for the urban space of the city of Logroño.

Most of the wind variations are caused by the presence of different roughness on the ground, which in the urban environment are high. Therefore it is considered a roughness length of three-quarters of the average height of buildings, where wind speed is assumed to be zero. Above, local barriers dominate the flow and an average wind speed cannot be considered until obtaining a roughness length of more than 20 times the height of the zone of disturbance.

The roughness length is the distance above the ground at which wind speed theoretically should be zero. Once this boundary layer is over passed, wind speed depends on the height approximately in the same way than in absence of the roughness of the terrain. The same idea can also be expressed through the concept of class of roughness. A high roughness class 3 or 4 refers to a landscape with many trees and buildings, while the sea surface roughness corresponds to a class 0 .

The area of disturbance of the buildings is approximately 1 meter for buildings of 10 meters in length. Up to 30 meters, local barriers dominate the flow. Above this height, for higher wind speeds and without inversion of air temperature, a logarithmic velocity profile is considered.

The consequences of shelter effect, due to the obstacles (in this case buildings) around the site, should also be taken into consideration. The greater the height above the top of the barrier, the shorter the shelter effect, and in general the shelter effect decreases when moving away from the obstacle. Therefore, in response to this effect, singular buildings (high and with clear environment) will be chosen preferably.

The power of a turbine depends on the wind speed cubed and therefore wind must be high enough. This will be achieved in buildings exceeding about 3 times the roughness length, having an approximate height of 30 meters.

The wind is rising around the buildings. At the top of a building wind speeds can be up to $20-30 \%$ higher compared with thw wind in an undisturbed site at the same height. The absolute wind speed in a building is higher the less wild is the environment of the building.

If the wind turbine is placed in the area of highest wind speed, the speed increase will be affected by the factor

$C T=1,2$

where TC is the increase factor of the roof (coefficient obtained by the authors). In these terms, the increased power is 1.7 (cube of the speed increase) when compared to other turbine located at the same height but without building. For the urban space of Logroño Table 2 has been developed, in which the speed increase due to that factor can be appreciated.

\section{Description of two-dimensional model of wind flow on decks of buildings}

Placing the wind turbine on top of the roof limits its size to a maximum of about $20 \%$ of the height of the building in order to improve the utilization of the wind speed increases that happen:

$D \leq 0,2 . h$

$D(\mathrm{~m})$ represents the diameter of the wind turbine and $h$ (m) the height of the building. The turbines of this size generally do not require significant modifications in the building structure, which is obviously an advantage. 
Table 2 Tabular data for the wind characterization of the urban space of Logroño, taking into account the intrinsic influence of the building $(\mathrm{Zr}=15 \mathrm{~m}, \alpha=0.39, \mathrm{CT}=1.2, \mathrm{k}=2.24)$

\begin{tabular}{cccc}
\hline $\boldsymbol{Z}(\boldsymbol{m})$ & $\boldsymbol{C z}$ & $\boldsymbol{c}(\boldsymbol{m} / \boldsymbol{s})$ & $\boldsymbol{v}(\boldsymbol{m} / \mathbf{s})$ \\
\hline $\mathbf{1 5}$ & 1,00 & 3,24 & $\mathbf{2 , 8 8}$ \\
$\mathbf{1 8}$ & 1,07 & 3,48 & $\mathbf{3 , 0 9}$ \\
$\mathbf{2 1}$ & 1,14 & 3,69 & $\mathbf{3 , 2 8}$ \\
$\mathbf{2 4}$ & 1,20 & 3,89 & $\mathbf{3 , 4 6}$ \\
$\mathbf{2 7}$ & 1,26 & 4,07 & $\mathbf{3 , 6 2}$ \\
$\mathbf{3 0}$ & 1,31 & 4,25 & $\mathbf{3 , 7 7}$ \\
$\mathbf{3 3}$ & 1,36 & 4,41 & $\mathbf{3 , 9 2}$ \\
$\mathbf{3 6}$ & 1,41 & 4,56 & $\mathbf{4 , 0 5}$ \\
$\mathbf{3 9}$ & 1,45 & 4,70 & $\mathbf{4 , 1 8}$ \\
$\mathbf{4 2}$ & 1,49 & 4,84 & $\mathbf{4 , 3 0}$ \\
$\mathbf{4 5}$ & 1,53 & 4,97 & $\mathbf{4 , 4 2}$ \\
$\mathbf{4 8}$ & 1,57 & 5,10 & $\mathbf{4 , 5 3}$ \\
$\mathbf{5 1}$ & 1,61 & 5,22 & $\mathbf{4 , 6 4}$ \\
$\mathbf{5 4}$ & 1,65 & 5,34 & $\mathbf{4 , 7 5}$ \\
$\mathbf{5 7}$ & 1,68 & 5,45 & $\mathbf{4 , 8 5}$ \\
$\mathbf{6 0}$ & 1,72 & 5,56 & $\mathbf{4 , 9 5}$ \\
$\mathbf{6 3}$ & 1,75 & 5,67 & $\mathbf{5 , 0 4}$ \\
$\mathbf{6 6}$ & 1,78 & 5,77 & $\mathbf{5 , 1 3}$ \\
$\mathbf{6 9}$ & 1,81 & 5,88 & $\mathbf{5 , 2 2}$ \\
$\mathbf{7 2}$ & 1,84 & 5,97 & $\mathbf{5 , 3 1}$ \\
\hline & & & \\
\hline
\end{tabular}

A series of simulations have been made with the application FLUENT (C) (Computational Fluid Dynamics) for evaluation and validation of the roof increasing factor, CT.

Let us analyse Figures 1 to 5. The flow separates at the edge of the building and forms a separation bubble with low speeds in the top and sides of the building. Outside the separation bubble, the wind speed increases. The wind velocity vector is not parallel to the roof but at an angle to the horizontal, named separation angle. As a result, the wind acceleration vector makes an angle of separation to the roof or the sides of the building, which depends on the size of the building and the wildness of their surroundings.

There exists a simple two-dimensional model for the description of this separation bubble, developed by [10], and applied to hexagonal buildings:

$y=0,28 \cdot H^{\frac{2}{3}} \cdot x^{\frac{1}{3}}$

Where $y$ is the height of the bubble separation (m) above the building, $H$ the height of the building (m), and $x$ the horizontal distance downwind from the facing facade (m).

More recently, [8] developed the model by extending it to three dimensions using the method of computational fluid dynamics.

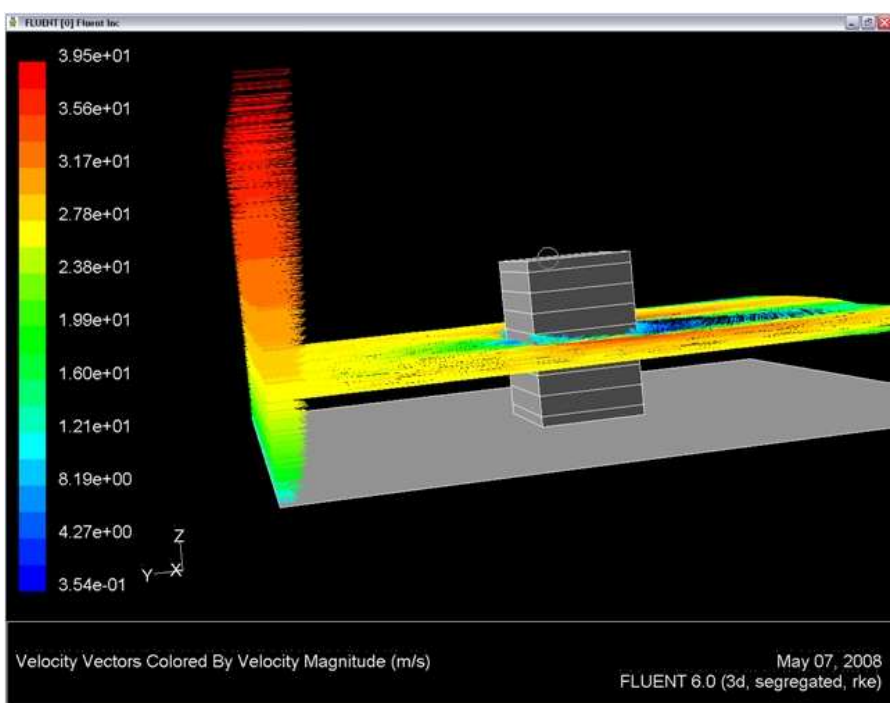

Figure 1 Modification in the wind flow in the horizontal plane due to the presence of a building. Simulation obtained with the application FLUENT (C) (Computational Fluid Dynamics).

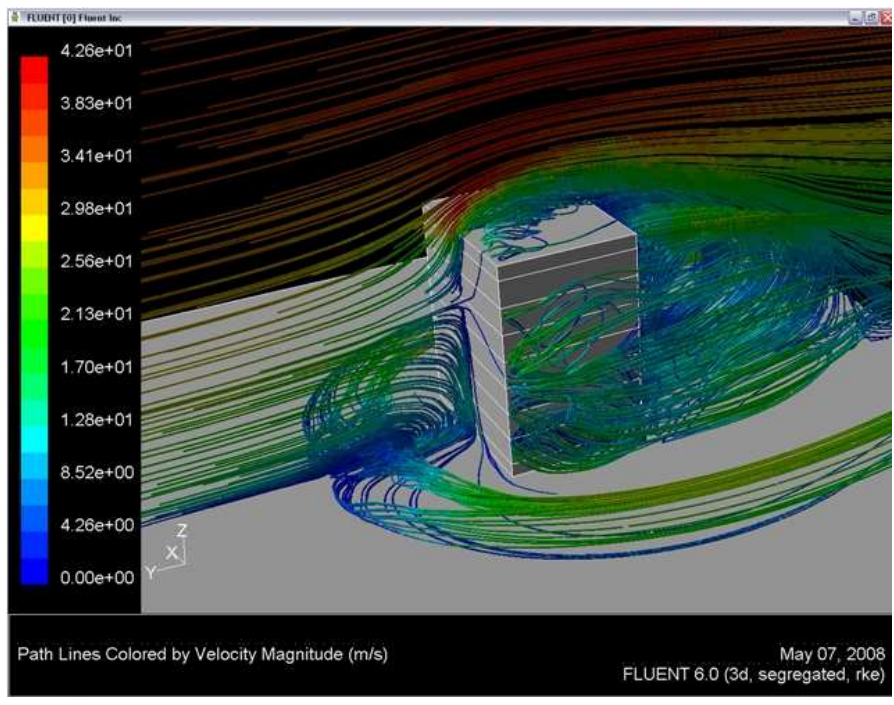

Figure 2 Modification in the wind flow in the vertical plane due to the presence of a building. Simulation obtained with the application FLUENT () (Computational Fluid Dynamics).

The two-dimensional model of the bubble separation has been applied to the DB. The values of Equation 1 are tabulated in Table 3, and they are graphically represented in Figure 4. 


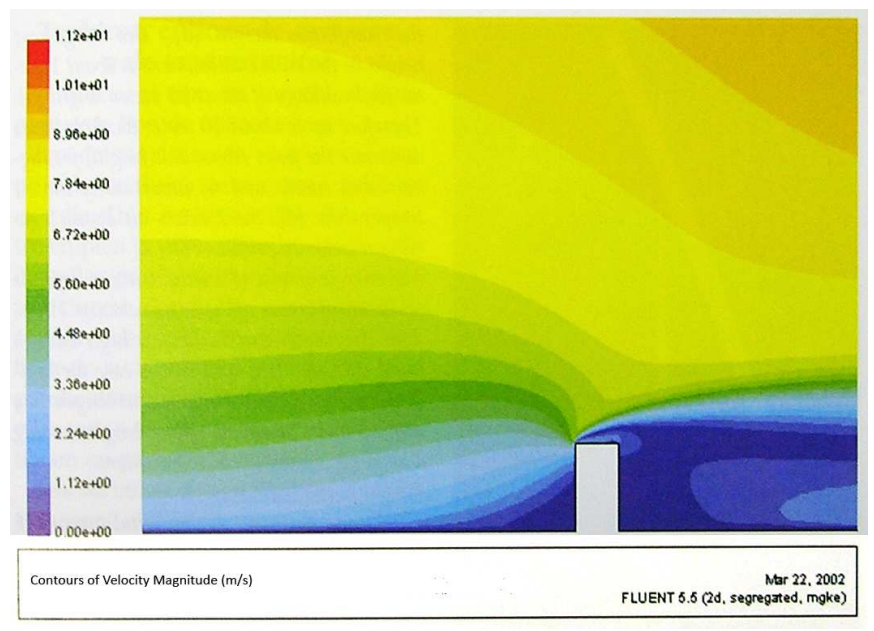

Figure 3 Modification in the wind flow in the vertical plane due to the presence of a building. Simulation obtained with the application FLUENT (C) (Computational Fluid Dynamics).

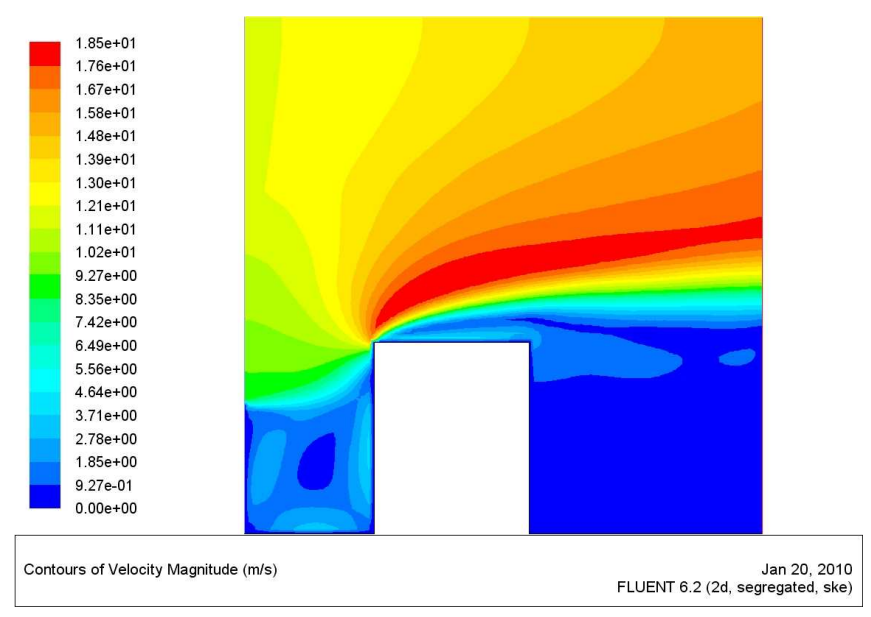

Figure 4 Modification in the wind flow in the vertical plane due to the presence of a building. Simulation obtained with the application FLUENT (C) (Computational Fluid Dynamics).

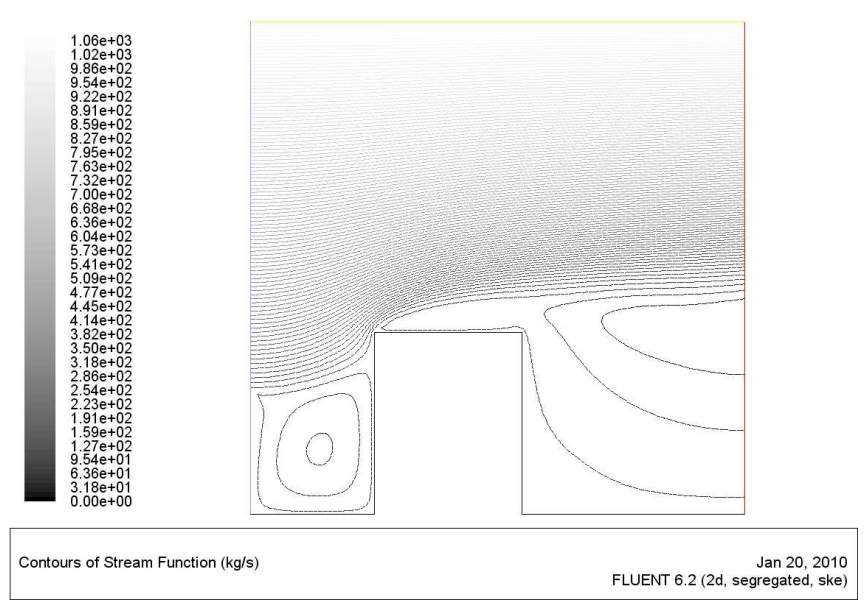

Figure 5 Wind flow lines in the vertical plane around a building. Simulation obtained with the application FLUENT @ (Computational Fluid Dynamics).
Table 3 Coordinates obtained from Equation (1) applied to DB

\begin{tabular}{ccc}
\hline $\boldsymbol{H}(\boldsymbol{m})$ & $\boldsymbol{x}(\boldsymbol{m})$ & $\boldsymbol{y}(\boldsymbol{m})$ \\
\hline 18,39 & 0 & 0,00 \\
18,39 & 1 & 1,95 \\
18,39 & 2 & 2,46 \\
18,39 & 3 & 2,81 \\
18,39 & 4 & 3,10 \\
18,39 & 5 & 3,34 \\
18,39 & 6 & 3,54 \\
18,39 & 7 & 3,73 \\
18,39 & 8 & 3,90 \\
18,39 & 9 & 4,06 \\
18,39 & 10 & 4,20 \\
18,39 & 11 & 4,34 \\
18,39 & 12 & 4,47 \\
18,39 & 13 & 4,59 \\
18,39 & 14 & 4,70 \\
18,39 & 15 & 4,81 \\
18,39 & 16 & 4,92 \\
18,39 & 17 & 5,02 \\
18,39 & 18 & 5,11 \\
18,39 & 19 & 5,21 \\
18,39 & 20 & 5,30 \\
\hline
\end{tabular}

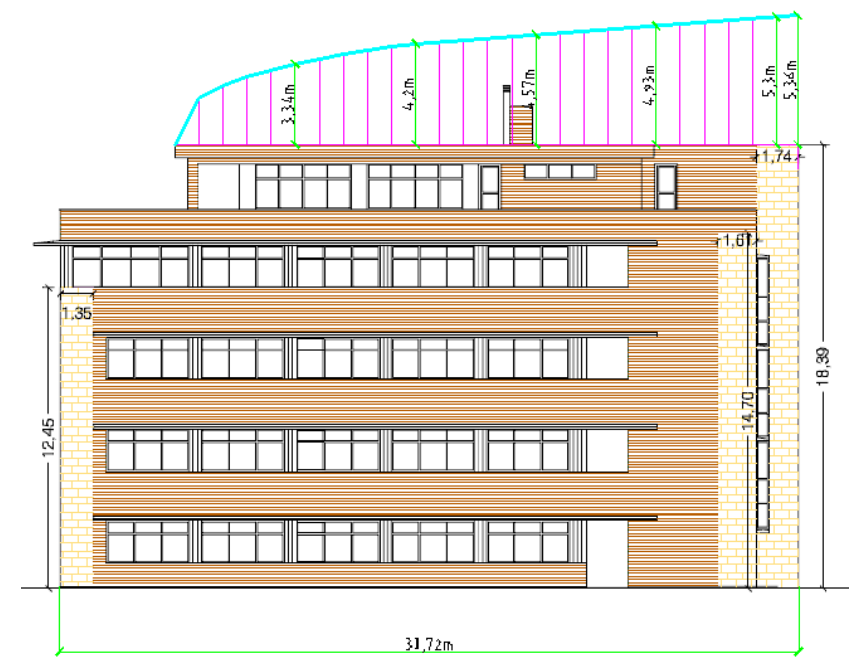

Figure 4 Modelling of the bubble separation in the south facade of the DB

\section{Wind turbines}

Researching different models, the following very important conclusions have been reached. The separation angle is greater near the edge of the roof of the building and varies with wind speed. The higher the building (both in height and diameter or plant), the greater the separation angle, reaching as far $90^{\circ}$. For low buildings that angle will be imperceptible. The more rugged is the area near the building the lower the angle of separation. 
The wind turbines should be placed always at a height above the separation bubble, in order to avoid the slow speeds and the significant turbulences.

The placement of wind turbines on the ledges of the building need only be at the height of them if they are placed in the direction of the prevailing winds of the area. But they will be in the bubble for the rest of the wind directions; so it is proposed to put them always above the bubble in order to take advantage of all directions. In the DB this height is $5.36 \mathrm{~m}$. The greater the height of the building and largest plant, the height of the bubble is increasing, as seen in Table 4. So in some cases may be interesting to put them on the ledge of the dominant direction of winds, at the expense of capturing less energy from other directions. For the urban space of Logroño (see Figure 5), the optimal cornice of the facade is the WNW, and secondly the ESE. For a building square or rectangular oriented toward the cardinal points, such as DB, the optimal fronts are firstly $\mathrm{W}$ and secondly E.

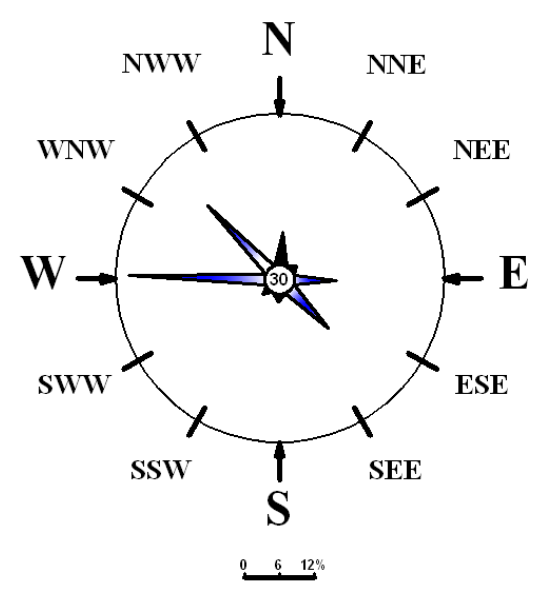

Figure 5 Implementation of the Rose of winds in the city of Logroño to locate wind turbines

The wind turbines located in the centre of the roof must be elevated above the horizontal by the same criterion. This height in the department building is $5.36 \mathrm{~m}$.

The diameter of the turbine rotor should not be greater than $10 \%$ of the diameter of the building.

\section{Conclusions}

Outside the separation bubble, the wind speed increases. This increase is about $20 \%$ of the wind speed that corresponds to that height. The vector of wind velocity is not parallel to the roof but presents an angle with the horizontal plane, the separate-ion angle. As a result, the acceleration vector of wind forms an angle of separation to the roof or to the sides of the building, which depends on the size of the building and the wildness or rugged of their surroundings.

The following conclusions have been obtained from this line of research based on the obtained models. The separation angle is greater near the edge of the roof of the building and varies with wind speed. The higher the building (both in height and diameter or plant), the greater the separation angle reached, reaching even $90^{\circ}$. For low buildings that angle will be imperceptible. The more rugged is the area near the building the lower the angle of separation.

Table 4 Height increment (m) above the building height (m) for optimal deployment of wind turbines on buildings of different plants $\left(\mathrm{m}^{2}\right)$

\begin{tabular}{|c|c|c|c|c|c|}
\hline $\begin{array}{l}\text { Altura } \\
\text { Edificio } \\
\text { (m) }\end{array}$ & $\begin{array}{c}\text { Altura }(m) \\
\text { Turb } \\
\text { PI. 10x10 }\end{array}$ & $\begin{array}{c}\text { Altura(m) } \\
\text { Turb } \\
\text { PI. 20x20 }\end{array}$ & $\begin{array}{c}\text { Altura(m) } \\
\text { Turb } \\
\text { Pl. 30x30 }\end{array}$ & $\begin{array}{c}\text { Altura(m) } \\
\text { Turb } \\
\text { Pl. 40x40 }\end{array}$ & $\begin{array}{c}\text { Altura(m) } \\
\text { Turb } \\
\text { Pl. 50x50 }\end{array}$ \\
\hline 15 & 3,67 & 4,62 & 5,29 & 5,82 & 6,27 \\
\hline 18 & 4,14 & 5,22 & 5,98 & 6,58 & 7,08 \\
\hline 21 & 4,59 & 5,79 & 6,62 & 7,29 & 7,85 \\
\hline 24 & 5,02 & 6,32 & 7,24 & 7,97 & 8,58 \\
\hline 27 & 5,43 & 6,84 & 7,83 & 8,62 & 9,28 \\
\hline 30 & 5,82 & 7,34 & 8,40 & 9,25 & 9,96 \\
\hline 33 & 6,21 & 7,82 & 8,95 & 9,85 & 10,61 \\
\hline 36 & 6,58 & 8,29 & 9,49 & 10,44 & 11,25 \\
\hline 39 & 6,94 & 8,74 & 10,01 & 11,01 & 11,86 \\
\hline 42 & 7,29 & 9,18 & 10,51 & 11,57 & 12,46 \\
\hline 45 & 7,63 & 9,62 & 11,01 & 12,11 & 13,05 \\
\hline 48 & 7,97 & 10,04 & 11,49 & 12,65 & 13,62 \\
\hline 51 & 8,30 & 10,45 & 11,96 & 13,17 & 14,19 \\
\hline 54 & 8,62 & 10,86 & 12,43 & 13,68 & 14,74 \\
\hline 57 & 8,93 & 11,26 & 12,89 & 14,18 & 15,28 \\
\hline 60 & 9,25 & 11,65 & 13,33 & 14,68 & 15,81 \\
\hline 63 & 9,55 & 12,03 & 13,78 & 15,16 & 16,33 \\
\hline 66 & 9,85 & 12,41 & 14,21 & 15,64 & 16,85 \\
\hline 69 & 10,15 & 12,79 & 14,64 & 16,11 & 17,35 \\
\hline 72 & 10,44 & 13,15 & 15,06 & 16,57 & 17,85 \\
\hline
\end{tabular}

The wind turbines have to be placed always at a height above the separation bubble, in order to avoid the slow speeds as well as significant turbulences. Furthermore it is noteworthy that the wind turbines will benefit from an increase of $20 \%$ of air velocity compared with the wind at the same location if there was no effect of the building. That is, the urban space provides an extra increase of wind power, provided that the location of wind turbines is optimised.

The study of the two-dimensional model of wind flow for building decks allows the optimisation of the implementation of mini wind turbines in the urban space.

Besides urban areas, due to the acceleration produced by the buildings on the wind speed, adds extra wind power increase, provided that the location of wind turbines is optimised. 


\section{References}

[1] Akula Venkatram, Marko Princevac, "Using measurements in urban areas to estimate turbulent velocities for modeling dispersion", Atmospheric Environment, Volume 42, Issue 16,pp.3833-3841, 2008.

[2] Andrew Grant, Cameron Johnstone, Nick Kelly, "Urban wind energy conversion: The potential of ducted turbines", Renewable Energy, Volume 33, Issue 6, pp. 1157-1163, 2008.

[3] Blanco,J.M., Sáenz-Díez,J.C., "Sistema de captación y tratamiento de datos meteorológicos para la aplicación a la generación eléctrica proveniente de energía eólica”, XII Reunión de grupos de investigación en ingeniería eléctrica, 2002.

[4] K.M. Lam, M.Y. H. Leung, J.G. Zhao Interference effects on wind loading of a row of closely spaced tall buildings Journal of Wind Engineering and Industrial Aerodynamics, 96(5) pp.562-583 2008

[5] K. Kashiyama, T. Takada, H. Miyachi "Large Scale Finite Element Modeling, Simulation and Visualization for Wind Flows in Urban Area Using Virtual Reality", Tsinghua Science \& Technology, Vol. 13, Supplement 1,Pages 84-89, 2008.

[6] N. Mithraratne, "Roof-top wind turbines for microgeneration in urban houses in New Zealand", Energy and Buildings, 41(10) pp 1013-1018, 2008.

[7] Sáenz-Díez,J.C.,Blanco,J.M., "Energías renovables para particulares", I Jornadas eólicas Derrioja,pp.5168, 2001.

[8] Sander Mertens, "Wind Energy In The Built Environment: Concentrator Effects Of Buildings Delf University of Technology", 2007

[9] Suresh H. Jangamshetti, V.Guruprasada Rau, "Normalized Power Curves as a Tool for Identification of Optimum Wind Turbina Generator", Parameters IEEE TRANSACTIONS ON ENERGY CONVERSION,VOL.16,NO.3, 2001.

[10] Wilson, R.E. and Lissaman, P.B.S., "Applied Aerodynamics of Wind Power Machines", NTIS PB 238594, Oregon State University, 1974. 